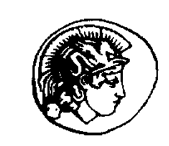

PERGAMON

Higher Education Policy 11 (1998) 1-2

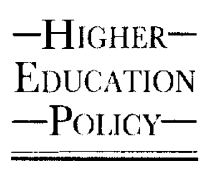

\title{
EDITORIAL
}

\section{THE COORDINATION OF HIGHER EDUCATION SYSTEMS}

How systems of higher education are coordinated, by what instruments operating at which level and to what end is one of the abiding and constant issues which society and its leaders and universities and their leaders have to face up to. And never more so than over the past ten to fifteen years. From the time Burton Clark launched his by now classic 'Triangle of Coordination' which characterised higher education systems in terms of the balance between the three forces of the State, the Market and Academic Oligarchy, scholars and analysts have scrutinised national systems of higher education to see how far they have moved away from the historic nexus of coordination grounded in the State and Academic Oligarchy towards coordination driven by the market. It is a delicate if not always rewarding task. For if the original hopeand the rhetoric which accompanied the drive towards 'market forces', consumer demand -was a powerful influence indeed in shaping the belief that national regulation might be attenuated and greater initiative conceded to the individual institution, the subsequent development did not always lead towards the promised land of diminished control. Certainly, what it has led to is a different kind of control, one formed around indicators of performance, of academic productivity, of cost rather than the historically blunt instruments of ministerial decree and circular.

Indeed, there is a very good case to be made for arguing that instruments such as these whilst they do not necessarily place the same weight on the formal homogeneity in procedure which was the major premiss underlying control from central national administration, nevertheless are far more sensitive and effective in forcing an outward appearance of compliance than was ever the case when based on the formal rigours of legal enactment alone. There is, in short, a certain parallel to be drawn between changes in the modes of system coordination and the edifying tale told by Aesop and revamped several centuries later by Jean de La Fontaine, of King Log and King Stork. Though whether the universities are wholly and justifiably to be compared with the Frogs who wanted a king, is a rather different matter.

It is, of course, now very clear that the dichotomy between State and Market is in operational rather than rhetorical terms, rather less clear than was once believed. And this is most particularly so when central government decides that it will act as if it were a species of market or, which often comes to very much the same thing, when it believes that it has the duty to inject into a reluctant university world by regulation the benefits of market responsiveness which otherwise the market would be enable to enforce on its own.

This has led to what might, if one were of an old fashioned turn of mind, be termed certain 'contradictions'. Not least amongst them is the increasing depth and 
penetration of the various 'mechanisms of coordination' themselves, whether they are called Evaluation Committees, Quality Councils. Funding Councils or Accreditation Agencies-a species of delegated layer of coordination, verification and oversight which, if not always located in the seat of government or in the appropriate branch of the Ministry or the Federal Authority is nevertheless striking in the influence it wields over the fate of individual institutions.

In this number of Higher Education Policy, the issue of coordination and the fluctuating boundaries between institutional initiative and systems of national oversight are explored across a number of widely different settings. Not surprisingly, by the nature of the topic, it cannot be exhausted. One may, however, keep a watchful eye if only to see how far what is sometimes termed 'remote surveillance' does not revert, once again, to detailed oversight. 